\title{
Settling the Matter on Indian Soil: Frictions between WHO and UNICEF over Vaccination against Tuberculosis, 1947-51.
}

\author{
Niels Brimnes
}

$\mathrm{I}$ t is seductively easy to portray the first two decades after the Second World War as the period when the WHO and UNICEF in unison took the lead in international health and jointly rolled out a number of initiatives against yaws, malaria and tuberculosis in developing countries. Maggie Black's semi-official account of UNICEF, The Children and the Nations, describes these efforts under headlines such as 'A Great Humanitarian Adventure' and 'The Mass Onslaught on Disease $^{2}$ while Amy Staples lauds the WHO in these decades as 'an international manager in health matters' which, through co-operation with other agencies, was able to extend its influence. In such accounts the relationship between the two organisations is described as one of mutual benefit where they 'shared many of the same operational priorities' and in which UNICEF provided the supplies and the WHO the technical advice and medical personnel. ${ }^{3}$

To the credit of Maggie Black she does refer at some length to early frictions between WHO and UNICEF. These are described as mainly related to issues of money and 'territory', namely about which organisation was entitled to available funds, and which organisation was in control of the field of 'health' within the UNsystem. Black's account suggests that the friction was largely overcome in the service of higher goals, arguing that 'the purpose of the two organisations was to further health among the peoples, the nations and the children, and issues of territory were

1 This article further elaborates and reframes arguments and analyses, which have been presented previously in different forms and contexts. See Niels Brimnes, "Vikings against Tuberculosis. The International Tuberculosis Campaign in India 1948-51", Bulletin of the History of Medicine, 81, 2 (2007), 407-430; Niels Brimnes, "BCG vaccination and WHOs global strategy for tuberculosis control 1948-83", Social Science \& Medicine, 67 (2008), 863-73; Niels Brimnes, Languished Hopes. Tuberculosis, the State and International Assistance in Twentieth-century India (New Delhi: Orient Blackswan, 2016).

2 Maggie Black, The Children and the Nations. The Story of Unice,, (UNICEF, 1986).

3 Amy L. S. Staples, The Birth of Development. How the World Bank, Food and Agriculture Organization, And world Health Organization changed the world 1945-65 (Kent: Kent State University Press, 2006), 154-55. 
minor compared with the overall good'. ${ }^{4}$ This statement is followed in her work by a description of the seemingly frictionless working relationship mentioned above. Black also touches upon disagreements between the WHO and UNICEF which were not about resources or political power, but were rooted in fundamentally different approaches to international health. This was the difference between, in Black's terminology, 'technical assistance' and 'material assistance', the former focused on the transfer of technology and know-how to build up sustainable health infrastructures in developing countries and the latter being driven by a more immediate concern to supply food, drugs and vaccines. ${ }^{5}$ Given its original status as a temporary emergency fund it is not surprising that UNICEF represented the latter approach, while the WHO saw itself as a provider of 'technical assistance'.

James Gillespie has explored this friction, using the joint efforts of the WHO and UNICEF in maternal and child health as his case-study. He concludes that despite efforts from the WHO to focus efforts on integrating a broader social and public health framework 'the focus remained on providing cheap and effective food supplements. ${ }^{6}$ A major reason for the triumph of UNICEF's supply-oriented approach was that it, much to the detriment of WHO, inherited ample funds from the UN relief and refugee organisation UNRRA. ${ }^{7}$ In this way Gillespie demonstrates how institutional rivalry over funding and authority had implications for the kind of international health work that actually came to be conducted in the field.

Gillespie refers in passing to the efforts to control tuberculosis as another area where the approaches and interests of WHO and UNICEF collided. ${ }^{8}$ This article takes up the case of tuberculosis, and more specifically BCG vaccination, to further examine the tensions and contradictions between the WHO and UNICEF immediately after the Second World War. First, it shows that the two organisations had different views on the introduction of BCG in global tuberculosis control. The analysis then moves to the extensive and complicated BCG campaign in India, conducted by the Scandinavian vaccination initiative The International Tuberculosis Campaign (ITC). The paper argues that the tension between the WHO and UNICEF impacted on the nature of the campaign so that it became neither a short term demonstration campaign nor a systematic mass vaccination

4 Black, The Children, 52-3.

5 Black, The Children, 80-1. The term 'technical assistance' is ambiguous; in some contexts it might be taken as referring to assistance, which give priority to technological solutions. To Black the difference is between the transfer of knowledge (technical assistance) and goods (material assistance). For a different use of technical assistance, see Sunil S. Amrith, Decolonizing International Health. India and Southeast Asia 1930-65 (Basingstoke: Palgrave, 2006).

6 James A Gillespie, "International Organizations and the Problem of Child Health", DYNAMIS 23 (2003), 142.

7 Gillespie, "International Organizations", 133-34.

8 Gillespie, "International Organizations", 134. 
effort. The article ends with an analysis of a renewed dispute over the position of BCG in tuberculosis control which emerged as the two organisations prepared to take over from the ITC as the major international partners in India's efforts to control tuberculosis. Generally, UNICEF's approach prevailed, suggesting that its greater financial strength was decisive for the nature of anti-tuberculosis work conducted in India and beyond during the 1950s.

\section{Accepting BCG}

The way mass vaccination with BCG against tuberculosis became one of the main activities in post-war international health is an early, illustrative example of the power relations between WHO and UNICEF. Prompted by the post-war rise of tuberculosis in Europe the Danish Red Cross, backed and funded by the Danish state, began to vaccinate with BCG in Poland, Hungary and Schleswig-Holstein in the spring of 1947. Later that year sister organisations from Norway and Sweden, together with UNICEF, began negotiations with the Danes about joining the initiative. On March 1948 UNICEF's executive board donated $\$ 4$ million to mass BCG vaccination campaigns, stipulating that half of the money must be spent outside Europe. In July The International Tuberculosis Campaign (ITC) was formally established as a joint enterprise between the three Scandinavian organisations and UNICEF. Mass BCG vaccination would become one of the major global health interventions in the first fifteen years after the Second World War. ${ }^{9}$

But BCG was a controversial choice as both the safety and the efficacy of the vaccine was questioned. Developed in the Pasteur institutes by French scientists Calmette and Guerin, BCG was first used on humans as early as 1921. Because it was the first vaccine based on living, attenuated bacteria there was a concern that the vaccine might cause tuberculosis rather than prevent it, and before 1945 its use, at least in western countries, was both cautious and limited..$^{10}$ Doubts about the safety of BCG were amplified in 1930 when seventy-six infants died shortly after vaccination in Germany. Investigations established that the deaths were due to an unfortunate mix between the vaccine and unattenuated tuberculosis bacteria, but in the broader public suspicion towards BCG lingered on into the post-war years. By 1947 most experts believed that the vaccine was safe but disagreements over its

9 Brimnes, "Vikings", 409-13.

10 BCG seems to have been much more used in Asia. Between 1926 and 1931 300,000 were given BCG in French Indochina, while nearly 400,000 were vaccinated in Japan during WWII. Laurence Monnais, "Preventive Medicine and 'Mission Civilisatrice'. Uses of the BCG Vaccine in French Colonial Vietnam between the Two World Wars", International Journal of AsiaPacific Studies, 2, no. 1, 2006, 57; William Johnston, The Modern Epidemic. A History of Tuberculosis in Japan (Cambridge, MA: Harvard University Press, 1995), 284. 
efficacy remained. While advocates of BCG maintained that it provided 80 per cent protection against tuberculosis influential voices, particularly in the United States, doubted that the vaccine had any protective effect at all. ${ }^{11}$

In this context the $\mathrm{WHO}$ was hesitant to endorse the emerging mass vaccination initiative. There were 'clinical' reservations linked to the issues of the safety and efficacy of the vaccine, but those at the organisation also wavered because they had a preference for more comprehensive programmes. In August 1947 the WHO's Expert Committee on Tuberculosis made specific reference to the Scandinavian mass vaccination drive, and while this initiative was approved, it emphasized that the programme should be seen as an emergency measure only and not as a substitute for other more durable approaches. The committee preferred to send out expert teams for short-term periods to demonstrate how to build sustainable, longer-term control programmes. ${ }^{12}$ UNICEF did not have similar reservations. Mass vaccination was ideally suited to the needs of a temporary fund with ambitions of becoming permanent as it provided immediate and measurable results. Even if mass vaccination did not have an immediate effect on morbidity, it provided impressive numbers of children vaccinated and comforting narratives about reaching out to the world's most disadvantaged. Three months later the WHO's expert committee, possibly concerned about UNICEF taking the bolder initiatives in its core field, assessed BCG more positively but maintained that it should not 'take the place of other recognized methods of tuberculosis control'. Moreover, the WHO joined the ITC as technical advisor and established a tuberculosis research centre in Copenhagen in an attempt to clear the 'clinical' uncertainties of BCG. In July 1948 the first World Health Assembly made BCG an integral part of the organization's formal policy on tuberculosis control. ${ }^{13}$ In 1949 mass vaccination was in full swing and expanded beyond Europe as the ITC's large programme in India was launched in February. UNICEF paid for the supplies of vaccine and the WHO provided scientific approval and advice. The reservations of the WHO expert committee faded, but they were not entirely abandoned however. In 1950 it expressed the hope that mass vaccination could 'stimulate development of all other phases of tuberculosis control' and expected that the campaigns 'which had already accomplished so much for tuberculosis control and public health, may be continued

11 Brimnes, "BCG Vaccination", 864-65. For the origin of the belief that BCG provided 80 per cent protection, see Christian W. McMillen, Discovering Tuberculosis. A Global History 1900 to the Present (New Haven: Yale University Press, 2015), 71-83.

12 "Report of the Expert Committee on Tuberculosis", Bulletin of the World Health Organization, 1, 2 (1948), 208, 211.

13 'Expert Committee on Tuberculosis. Report of the Second Session', WHO Archives, IC/TBC/2; Official Records of the WHO, 13, 300. For a useful overview of the official WHO resolutions on tuberculosis, see World Health Organization, Handbook of Resolutions and Decisions of the World Health Assembly and the Executive Boara, I, Geneva: WHO, 1973), 85-88. 
at the same high level of quality and with the same extensive coverage of so many parts of the world'. ${ }^{14}$ Their eye was still fixed on the longer-term.

In this way the WHO cautiously embraced mass vaccination, despite continuing controversy about the value of the vaccine and despite reservations about mass vaccination as a manifestation of the quick technological fix. Helped by the independent initiative of the Scandinavians, UNICEF won this contest between a 'horizontal' system-oriented approach and a 'vertical' supply-oriented approach. 'Technical assistance' had lost out to 'material assistance' in tuberculosis control. The WHO was pushed to approve of a tuberculosis strategy which, contrary to its official commitment to the broader social and economic context of disease, focused almost exclusively on vaccination. ${ }^{15}$ The pivotal position of ITC director Johannes Holm as both chairman of the WHO expert committee and member of UNICEFs medical sub-committee obviously goes a long way to explaining why WHO came to this position. But the process also suggests that WHO had to 'follow the money' in the UNICEF coffers. As Gillespie has concluded 'the WHO was faced with the choice of developing its own approach to tuberculosis, but with no funding, or reluctantly join UNICEF's as technical adviser, on terms set by the fund'. ${ }^{16}$

\section{BCG vaccination in India}

The mass vaccination campaign in India was among the most extensive conducted by the ITC. In terms of population reached it was the third largest as only those in Poland and Germany reached more people. Financially the Indian campaign was surpassed only by the programmes in Poland and Yugoslavia (and presumably in Germany, for which no figure is available). Among the campaigns conducted outside Europe it was by far the largest as more than four million Indians received the prevaccination tuberculin test and almost a half a million dollars was spent. ${ }^{17}$ There was, however, always uncertainty about the nature and duration of the ITC's involvement in India. This might be seen as another manifestation of the friction between the WHO and UNICEF.

14 'Expert Committee on Tuberculosis. Report of the Fourth Session', WHO Technical Report Series, 7 (1950), 8; Expert Committee on Tuberculosis. Report of the Fifth Session', WHO Technical Report Series, 32 (1951), 9.

15 In the constitution of WHO, 'health' was defined in a strikingly broad way as 'a state of complete physical, mental and social well-being and not merely the absence of disease or infirmity'. See The first Ten years of the World Health Organization (Geneva: WHO, 1958), 459.

16 Gillespie, "International Organizations", 134. Black suggest that the centrality of Holm in both WHO and UNICEF funded ITC was a tactical move on the part of UNICEF to co-opt WHO into supporting BCG mass vaccination. Black, The Children, 51.

17 Brimnes, "Vikings", 408. 
In accordance with UNICEF priorities the ITC was prepared to vaccinate entire populations in European countries but this was not necessarily possible in large, populous developing countries. In November 1948 the Scandinavian co-ordination committee, the executive body of ITC, discussed this issue at some length. Four days earlier the ITC had entered into an agreement with the Government of India about the introduction of BCG. ITC Director Johannes Holm, who favoured a comprehensive mass campaign approach, noted the need to distinguish between campaigns conducted inside and outside Europe, and emphasized that 'UNICEF exists only for a limited time and cannot commit itself to long-term costs'. In many non-European countries, India being the prime example, the ITC's involvement would, Holm conceded, mainly be 'demonstrations aiming to train a large number of domestic doctors'. ${ }^{18}$ This was, it should be noted, close to the 'technical assistance' approach favoured by WHO. The Scandinavian doctors and nurses who began their work in India in early 1949 therefore believed that they were part of a six-month demonstration tour.

It was quickly realised, however, that this was vastly inadequate to make any impact in a country harbouring 15 per cent of the world population. ${ }^{19}$ As early as August 1949 the Government of India suggested that the agreement with ITC be extended to two years. Although he was not able to comply with this request Holm readily admitted that conditions in India were exceptional and that 'a campaign in India will have an impact only if mass vaccination is conducted on a colossal scale. ${ }^{20}$ In the end ITC remained in India for two and half years. But even with ample funding from UNICEF vaccinating South Asia with BCG was clearly more than the Scandinavians were prepared for, and by 1950 it became clear that ITC was going to withdraw from India. The ITC saw itself as an enterprise responding to an emergency in Europe, and to the UNICEF programme committee Holm explained that the ITC had concluded that elsewhere they were 'not dealing with true emergency situations; instead, it is felt that the work should be planned on a long term basis, proceeding step by step'. ${ }^{21}$ By distancing himself from assisting in longterm efforts to build health services Holm revealed that the ITC was much closer to UNICEF than to the WHO. However, Holm personally was not comfortable with

18 Proceedings of the 'Scandinavian Coordination Committee', 29. November 1948, 11. Private Archive no. 7369, Box 2 (C), Danish National Archives (hereafter DNA). My translation.

19 The population of the Indian Union in 1950 was above 350 million. Kingsley Davies, The Population of India and Pakistan (Princeton. Princeton University Press, 1951), 17. See also 'Central Bureau of Health intelligence data', at http://www.cbhidghs.nic.in/hia2005/1.01.htm, (accessed 7. December 2015).

20 Proceedings of the 'Scandinavian Coordination Committee', 13. August 1949, 8-9. Private Archive no. 7369, Box 2 (C), DNA. My translation.

21 'Statement by Dr. Johannes Holm for the Programme Committee on 3 November 1949', 1-2. Private Archive no. 7369, Box 2 (D), DNA 
the decision to withdraw from India. He deplored that the ITC's work was coming to an end in India, because the organisation had not yet shown 'how a real mass vaccination' could be carried out under the challenging circumstances there. ${ }^{22}$ The final section of this article reveals how Holm managed to influence the priorities of tuberculosis control in India, even after the ITC left the scene.

\section{Between Demonstration Centres and 'real' mass vaccination}

The only and obvious candidates to take over from the ITC in India were the WHO and UNICEF. Although the two organizations had followed ITC's activities closely, the transition was anything but smooth. Disagreements between the WHO on the one hand, and the ITC seconded by UNICEF on the other, over the future design of BCG vaccination materialized during the summer of 1950 . Eventually this meant that the ITC, which had planned to withdraw from India by the end of that year, had to extend its activities to the summer of 1951. The problems arose when WHO suggested that the three remaining international vaccination teams be attached to three tuberculosis demonstration centres that would be established with support from WHO and UNICEF in Delhi, Trivandrum and Patna. Their main task would be to train local teams. ${ }^{23}$ Establishment of such centres was given high priority in the WHO's general recommendations for tuberculosis control programmes and it was envisaged that each centre 'should undertake the training of basic personnel in all aspects of tuberculosis. ${ }^{24}$

The control demonstration centres were a further development of the multipurpose tuberculosis clinic which had occupied centre stage in Indian plans developed before 1947, when comprehensive vaccination campaigns had been a distant possibility. The influential Bhore Committee of 1946 described clinics as an essential link in the institutional framework to be set up to control tuberculosis and envisaged that the clinic will form the centre from which both curative and preventive work in tuberculosis will spread into the homes of the people'. ${ }^{25}$ In 1950 the Delhi tuberculosis clinic, which had been running a relatively successful pre-drug home treatment scheme was upgraded to a tuberculosis control demonstration centre through a donation from WHO and UNICEF. When fully extended the new

22 Proceedings of the 'Scandinavian Coordination Committee', 16. December 1950, 3-4. Private Archive no. 7369, Box 2 (C), DNA. English in original.

23 See for instance T.G. Davies (New Delhi) to Sam Keeny (Bangkok) 27. June 1950. Box CF/RA/BX/FD/1985/T001, folder C0038, UN Archives (UNICEF).

24 "Expert Committee on Tuberculosis. Report on the Fourth Session", WHO Technical Report Series, 7 (1950), 12.

25 Report of the Health Survey and Development Committee (Calcutta: Government of India Press, 1946), II, 161. See also Brimnes, Languished Hopes, 63-65. 
centre was to include curative, preventive, and laboratory sections. The preventive section was further divided into inter-related departments, mass radiography and BCG, 'the two modern weapons of tuberculosis control'. ${ }^{26}$ The tasks of the BCG department were described as follows:

The B.C.G. department, which apart from routine vaccination of contacts and as a general preventive measure in the areas ear-marked for public health control, will initiate a control programme of B.C.G. vaccination to study the efficacy of the methods in a given locality. Further it will be a training ground for technicians in field work, and could undertake investigations in testing and vaccination procedures which will be suitable for Mass Vaccination Programme in the country. ${ }^{27}$

The essential function of the new centre was described as initiating 'training schemes at the highest modern level, in order that such training may progressively expand and diffuse throughout the country with the ultimate aim of developing a fully integrated efficient national T.B. service' ${ }^{28}$ Moreover, the centre was supposed to be the training ground for tuberculosis workers from the entire South East Asian Region of the WHO. Essentially, the WHO was trying to 'claim back' the ideology behind the Indian tuberculosis control effort. Instead of continuing the narrow 'vertical' mass vaccination approach, which was tailor-made to serve UNICEF interests, the WHO insisted that the future belonged to broader, 'horizontally' oriented schemes, of which mass vaccination was only one element.

At a meeting of UNICEF's medical subcommittee in August 1950 in which representatives of the WHO and the ITC participated, it became clear that the WHO was not ready to continue mass BCG vaccination along the lines developed by the Scandinavians. In November a UNICEF liaison officer noted that 'the question [of] ... whether WHO is ready to assume responsibility for the further development of the campaigns remains still unanswered'. ${ }^{29}$ The ITC saw the situation in a similar light, concluding in December that while UNICEF was interested in continuing mass vaccination according to existing principles ' $\mathrm{WHO}$ is not prepared to take over to such a degree, ${ }^{30}$

The ITC was not content with the position of the WHO and Holm in particular was upset. He criticized the WHO's plans for mentioning 'BCG teams only in

26 The Tuberculosis Association of India, Twelfth Annual Report, 1950 (New Delhi, n.d.), appendix XI, "Report on the New Delhi TB Centre", 158.

27 The Tuberculosis Association of India, Twelfth Annual Report, 159.

28 The Tuberculosis Association of India, Twelfth Annual Report, 159.

29 B. Fraser (Copenhagen) to Karl Borders (New York), 7. September 1950; B. Fraser (Paris) to Karl Borders (New York), 3. November 1950. Both in Box CF/RA/BX/FD/1985/T001, folder C0038, UN Archives (UNICEF).

30 Proceedings of the 'Scandinavian Coordination Committee', 16. December 1950, 4. Private Archive no. 7369, Box 2 (C), DNA. English in original. 
connection with the three Indian Tuberculosis Centres to be established and they do not constitute plans either for a mass campaign in the real sense or for demonstration work on a scale such as ITC has been conducting it'. ${ }^{31}$ Holm's protest is not surprising as the WHO plans constituted a challenge to a campaign infrastructure of which he had been one of the main architects. Not surprisingly UNICEF agreed with Holm and the ITC and the former's liaison officer described the WHO plans as a system that did not 'augur well, either for economy or success in general'. ${ }^{32}$ In October 1950 it seemed that the ITC and UNICEF would lose the contest with WHO, which seemed unprepared to compromise. ${ }^{33}$

In the spring of 1951 the issue remained unsettled because the WHO could not proceed without UNICEF funding. UNICEF planned a conference in Bangkok to discuss the fate of BCG vaccination in Asia and the ITC expressed the hope that the WHO would be convinced to actively support a 'real' mass vaccination campaign in India. ${ }^{34}$ The WHO obstructed the Bangkok conference, so negotiations between the WHO, UNICEF and the ITC took place in New Delhi in March. Holm reiterated that he preferred the training of new BCG teams be done in the field rather than at the demonstration centres and UNICEF's Regional Director, Sam Keeny, pressurised WHO to 'clarify' whether the organisation 'would support an extended mass vaccination scheme in India developed on the existing structure'. He further suggested that the issue of the relation between the campaign and the demonstration centres could be left open. Another UNICEF representative at the meeting was more assertive and hinted that the UNICEF Board "was not convinced that the money involved in Diagnostic Centres was a good investment because it was their impression that anti-Tuberculosis measures had not been devised on a scale which was economically possible for a country like India to support'. In other words UNICEF did not believe that India could afford the type of programme advocated by WHO and as mass vaccination was cheaper it was preferable. E. J. T. McWeeney from the WHO admitted that the three planned centres were inadequate, but opted for time 'to digest the lessons of the present set up from every possible angle'. Moving fast forward with BCG vaccination was clearly much more urgent for the UNICEF representatives, on whose behalf Keeny urged that the vaccine 'should be pushed

31 Letter from Holm to Dr. Eliot of WHO, quoted in B. Fraser (Copenhagen) to Karl Borders (New York) 26. October 1950. Box CF/RA/BX/PD/1947/T016, folder A137, UN Archives (UNICEF).

32 B. Fraser (Copenhagen) to Karl Borders (New York) 26. October 1950.

33 In November Fraser wrote that Holm appeared to have given up the struggle to save 'his' approach to BCG vaccination. B. Fraser (Paris) to Karl Borders (New York) 3. November 1950.

34 Proceedings of the 'Scandinavian Coordination Committee', 16. December 1950, 4. Private Archive no. 7369, Box 2 (C), DNA. English in original. 
forward and it should not be treated by Government as of lesser importance than other TB services'. ${ }^{35}$

Meanwhile Holm acted in the field. He made a lengthy trip to India in the spring of 1951 during which he attended the March meeting in New Delhi. He saw the main purpose of this trip to determine whether India was ready for mass vaccination. In a report to the co-ordination committee of the ITC he explained: 'Before starting out on this trip, I realized that there were only two alternatives open to ITC either to extend the BCG vaccination to a real mass campaign in India as in the rest of the ITC countries, or to abandon the campaign completely and withdraw from India as soon as possible'. ${ }^{36}$ During the trip Holm took the opportunity to transform the ITC campaign from demonstrations to travel as widely as possible in India, to localized mass vaccination of entire populations. Chosen for this 'experimental mass vaccination' were the cities of Meerut and Gwalior and the rural areas of Ambala district in the Punjab and Indore in Madhya Pradesh. Seeing that the number of tests and vaccinations went significantly up, Holm was quick to conclude that 'the ITC organization of mass campaigns can be used also in India'. ${ }^{37}$ There can be little doubt that Holm and the ITC tried their best to ensure that the UNICEF inspired supply oriented approach prevailed.

The disagreement over the future design of the BCG campaign was a third manifestation of the general tension between approaches to international health taken by the WHO and UNICEF. The WHO proposal was an attempt to make $B C G$ vaccination an integral part of a more diversified and less 'vertical' tuberculosis control scheme. ${ }^{38}$ The ITC and UNICEF, on the other hand, preferred to contain BCG within a single-purpose and focused mass vaccination campaign. Rather than integrating BCG with other tuberculosis control measures, they aimed to vaccinate as many as possible as quickly as possible.

\section{Conclusion}

Without knowing the exact outcome of the negotiations in New Delhi in March 1951 it seems clear that in the end the ITC and UNICEF also won this contest. In

35 'Minutes of a meeting held in the UNICEF India Mission House ... on March 21, 1951, to consider the future requirements and organisation of a BCG campaign in India', 3-5. Box CF/RA/BX/PD/1947/T016, folder A137, UN Archives (UNICEF).

36 'Report on Visit to India, February-April 1951', 2. Private Archive no. 7369, Box 4 (F.i/J. Holm), DNA.

37 Brimnes, "Vikings", p. 428

38 'Report of the Meeting of the Medical Subcommittee', 4. January 1950, 4. E/ICEF/R.10. See also 'Report of the Meeting of the Medical Subcommittee', 25-26. August 1950, 9. E/ICEF/R.78. Both in UN Archives (UNICEF). 
a report on the three tuberculosis demonstration centres written around 1955 BCGrelated activities were only referred to as 'planned' and among nearly 900 people trained at the centres before that year only seven were BCG vaccinators. ${ }^{39}$ By contrast, after the WHO and UNICEF had taken over from the ITC as international partners to the Government of India the BCG vaccination effort developed into the largest vaccination campaign the world had seen. In late 1953 the number of monthly tests surpassed one million and it reached nearly two million in late 1958, by which time one hundred and sixty-one vaccination teams operated throughout India. At times the optimism of the WHO senior medical officer Halfdan Mahler knew no limits. In a report from 1954 he cheered

What most of people denied and a few wishfully hoped has proved to be possible.

The past years' experience has shown that it is a realistic economically and technically proposal to tuberculin test the total young population in India within a five to seven year period and to vaccinate the non-reactors. BCG should therefore, potentially be able to influence the epidemiology of tuberculosis in India. ${ }^{40}$

Mahler's elation was premature. The campaign ran out of steam in the 1960s and coverage rates became frustratingly low. ${ }^{41}$ Later evidence was to raise questions about the efficacy of BCG vaccination altogether, as a large controlled trial in Chingleput in South India conducted from 1968 to 1978 suggested that BCG was in fact worthless as a preventive against pulmonary tuberculosis. ${ }^{42}$ But whatever the eventual outcomes of this massive programme, I have attempted to demonstrate that the campaign was not the result of the congenial cooperation between the WHO and UNICEF. Instead the nature of the efforts to control tuberculosis in India during the 1950s was to a large extent the result of the goals and the immediate financial power of UNICEF overriding the long-term public health strategy of the WHO.

Niels Brimnes, is Associate Professor in the Department of Culture and Society, University of Aarhus.

39 'Report on India TB-project UNICEF FEP-32'. Box CF/RA/BX/PD/1962/T009, folder A136, UN Archives (UNICEF).

40 H. Mahler, 'Quarterly field Report', 2nd quarter 1954, 25. July 1954, 9. Box CF/RA/BX/PD/1962/T008, folder A123, UN Archives (UNICEF).

41 For the development of BCG vaccination in India after 1960, see Brimnes, Languished Hopes, 210-76.

42 For details, see Brimnes, "BCG Vaccination". 


\title{
References
}

\author{
Archives
}

Danish National Archives (DNA)

UN Archives (UNICEF)

WHO Archives.

\section{Published sources}

Amrith, Sunil S., Decolonizing International Health. India and Southeast Asia 193665. Basingstoke, 2006.

Black, Maggie, The Children and the Nations. The Story of Unicef. UNICEF, 1986.

Brimnes, Niels. "Vikings against Tuberculosis. The International Tuberculosis Campaign in India 1948-51", Bulletin of the History of Medicine, 81, 2 (2007), 407-430

Brimnes, Niels. "BCG vaccination and WHOs global strategy for tuberculosis control 1948-83", Social Science \& Medicine, 67 (2008), 863-73.

Brimnes, Niels, Languished Hopes. Tuberculosis, the State and International Assistance in Twentieth-century India. New Delhi, 2016.

Davies, Kingsley, The Population of India and Pakistan. Princeton, 1951.

Gillespie, James A. "International Organizations and the Problem of Child Health", Dynamis, 23 (2003), 115-42.

Government of India, Report of the Health Survey and Development Committee. Calcutta, 1946.

Johnston, William, The Modern Epidemic. A History of Tuberculosis in Japan. Cambridge, 1995.

McMillen, Christian W., Discovering Tuberculosis. A Global History 1900 to the Present. New Haven, 2015.

Monnais, Laurence "Preventive Medicine and 'Mission Civilisatrice'. Uses of the BCG Vaccine in French Colonial Vietnam between the Two World Wars", International Journal of Asia-Pacific Studies, 2:1, (2006), 40-66.

Staples, Amy L.S., The Birth of Development. How the World Bank, Food and Agriculture Organization, and World Health Organization changed the world 1945-65. Kent, 2006.

The Tuberculosis Association of India, Twelfth Annual Report, 1950. New Delhi, undated.

WHO, "Report of the Expert Committee on Tuberculosis", Bulletin of the World Health Organization, 1:2 (1948), 208-11. 
WHO, Handbook of Resolutions and Decisions of the World Health Assembly and the Executive Board, 1. Geneva, 1973.

WHO, Expert Committee on Tuberculosis. Report of the Fourth Session, WHO Technical Report Series, 7. Geneva, 1950.

WHO, Expert Committee on Tuberculosis. Report of the Fifth Session', WHO Technical Report Series, 32. Geneva, 1951.

WHO, The first Ten years of the World Health Organization. Geneva, 1958. 